\title{
PENENTUAN PRIORITAS INDIKATOR DALAM MERENCANAKAN JALUR PEJALAN KAKI (STUDI KASUS: KAWASAN BLOK M, JAKARTA SELATAN)
}

\section{DETERMINING THE PRIORITY INDICATORS IN PEDESTRIAN-WAY PLANNING (CASE STUDY: BLOK M AREA, SOUTH JAKARTA)}

\author{
Hilman Gunung Mulia Pohan', Okto Risdianto Manullang ${ }^{2}$ \\ 'Suku Dinas Bina Marga, Kota Administrasi Jakarta Barat; hilgmp@yahoo.com \\ ²Departemen Perencanaan Wilayah dan Kota; Universitas Diponegoro, Semarang, Jawa Tengah; oktomanullang73@gmail.com \\ Info Artikel: \\ - Artikel Masuk: 18/02/2018 \\ - Artikel diterima: 02/07/2018 \\ - Tersedia Online: 10/10/2018
}

\begin{abstract}
ABSTRAK
Kawasan Blok M merupakan pusat kegiatan sekunder di wilayah Kota Administrasi Jakarta Selatan yang berfungsi sebagai pusat perkantoran, perdagangan dan jasa, dekat dengan permukiman yang memiliki daya tarik besar sebagai bangkitan dan tarikan lalu lintas, serta termasuk kawasan yang diprioritaskan untuk penanganan jalur pejalan kaki. Beberapa permasalahan kawasan Blok M yaitu adanya alih fungsi jalur pejalan kaki, kondisi geometri yang tidak ideal, tidak adanya street furniture, adanya hambatan pada jalur pejalan kaki, kondisi tekstur yang tidak rata, dan terdapat jalan yang belum memiliki jalur pejalan kaki. Tujuan utama dari penelitian ini adalah untuk menganalisis penentuan prioritas indikator dalam merencanakan jalur pejalan kaki agar sesuai dengan preferensi pejalan kaki dan preferensi para ahli terkait keamanan dan kenyamanan, sehingga dapat berfungsi secara optimal. Penelitian ini menggunakan analisis IPA terkait preferensi pejalan kaki dan analisis AHP terkait preferensi para ahli untuk merumuskan penentuan prioritas indikator dalam merencanakan jalur pejalan kaki yang aman dan nyaman. Berdasarkan hasil analisis terkait penentuan prioritas indikator dalam merencanakan jalur pejalan kaki yang meliputi analisis preferensi pejalan kaki dan preferensi para ahli terkait tingkat keamanan dan kenyamanan, terdapat perbedaan terhadap penentuan prioritas indikator dalam merencanakan jalur pejalan kaki. Berdasarkan preferensi pejalan kaki, peniadaan hambatan/ penghalang dan keberadaan street furniture sebagai prioritas utama indikator, di sisi lain kondisi permukaan (tekstur) dan aksesibilitas sebagai prioritas utama indikator yang disampaikan oleh para ahli.

Kata Kunci: Jalur Pejalan Kaki, Keamanan dan Kenyamanan, Preferensi
\end{abstract}

\begin{abstract}
Blok $M$ area as a function of secondary activity center in South Jakarta Municipality which serves as an office center, trade and service center, close to settlement that has a great appeal as trip generation, and includes areas that are prioritized for handling pedestrian-ways. Some problems in Blok $M$ area are the changing of pedestrian-ways function, geometric condition is not ideal, the absence of street furniture, the obstacles in the pedestrian-ways, uneven texture conditions, and there are roads that do not have a pedestrian-ways. The main purpose of the research is to analyze the prioritizing indicators in pedestrian-ways planning to suit the preferences of pedestrians and experts related to safety and comfort, so that they can function optimally. This research used IPA analysis related to pedestrians preferences and AHP analysis related to expert preferences to formulate the prioritizing indicators in pedestrian-ways planning of safe and comfort. The results of the analysis related to the prioritizing indicators in pedestrian-ways planning that include analysis of pedestrians preferences and experts related to safety and comfort levels, there are differences in preference to prioritizing indicators in pedestrianways planning between pedestrians and experts. Based on pedestrians preferences, removal of barriers and the existence of street furniture that become the priority of pedestrian-ways development key indicators, whereas based on experts preferences, surface conditions (texture) and accessibility that become the prioritizing indicators in pedestrian-ways planning.

Keyword: Pedestrian-Ways, Safety and Comfort, Preference
\end{abstract}

Copyright $\odot 2016$ GJGP-UNDIP

This open access article is distributed under a Creative Commons Attribution (CC-BY-NC-SA) 4.0 International license.

Cara men-sitasi (APA 6th Style):

Pohan, Hilman Gunung Mulia, \& Manullang, Okto Risdianto. (2018). Penentuan Prioritas Indikator dalam Merencanakan Jalur Pejalan Kaki (Studi Kasus: Kawasan Blok M, Jakarta Selatan. Jurnal Pembangunan Wilayah dan Kota, vol 14(3), 175-185 


\section{PENDAHULUAN}

Pemerintah Provinsi DKI Jakarta mulai tahun 2016 gencar untuk memperbaiki dan membangun jalur pejalan kaki (Kaban JSP, 2017). Pembangunan jalur pejalan kaki menjadi salah satu Misi Jakarta 2017-2022 yaitu "Menuju Jakarta Walkable 2022" dengan menciptakan ruang pejalan kaki yang lengkap, aman, nyaman, dan humanis, serta mendukung peningkatan penggunaan tranportasi publik. Tahun 2017 Dinas Bina Marga DKI Jakarta sudah melakukan perbaikan 47 jalur pejalan kaki di semua wilayah kecamatan. Anggaran yang dialokasikan sebesar Rp 400 miliar (Martiyanti, E., 2017). Kawasan Blok M merupakan pusat kegiatan sekunder di wilayah Kota Administrasi Jakarta Selatan. Rencana yang diprioritaskan di Kawasan Blok $M$ berupa penanganan jalur pejalan kaki. Hal ini dikarenakan kawasan ini berfungsi sebagai pusat kegiatan sekunder yang memiliki fungsi pengembangan stasiun terpadu dan titik perpindahan antar moda transportasi konsep Transit Oriented Development (TOD) (DKI Jakarta, 2014).

Pada tahun 2014, Dinas Bina Marga DKI Jakarta merencanakan perbaikan jalur pejalan kaki di Wilayah Jakarta Selatan terutama di sekitar wilayah Blok M seperti Jl. Sultan Iskandarsyah, Jl. Prapanca, Jl. Melawai, Jl. Pattimura, Jl. Kyai Maja, dan Jl. Barito (Anonim, 2014). Perbaikan yang dilakukan selama ini hanya berdasarkan pada permasalahan yang telah terjadi. Dalam perencanaannya pemerintah hanya melibatkan pendapat para ahli dan tidak mempertimbangkan pendapat pejalan kaki. Hal ini yang mengakibatkan pembangunan jalur pejalan kaki saat ini tidak sesuai dengan kebutuhan pejalan kaki. Sampai saat ini belum ada prioritas indikator yang digunakan untuk menjadi dasar penentuan dalam merencanakan jalur pejalan kaki terkait keamanan dan kenyamanan. Kriteria-kriteria jalur pejalan kaki yang aman dan nyaman dapat dilihat dari dua komponen utama, yaitu keamanan dan perlindungan, serta kebijakan terkait (Barman \& Daftardar, 2010).

Jalur pejalan kaki berfungsi sebagai komponen yang terintegrasi dengan sistem jalan yang ramah bagi pejalan kaki dimana mereka mendapatkan keamanan, kenyamanan, aksesibilitas, dan pergerakan yang efisien. Pembangunan jalur pejalan kaki sebaiknya bukan hanya sekedar pembangunan fisik saja, namun lebih diutamakan pada manfaat jalur pejalan kaki tersebut sebagai wadah untuk melakukan segala macam kegiatan yang dilakukan oleh penggunanya (Pratama, 2014). Ruang lalu lintas untuk pejalan kaki harus direncanakan sedemikian mungkin untuk memaksimalkan keamanan dan kenyamanan pergerakan harian mereka. Kualitas transportasi tidak bermotor termasuk jalur yang menerus, daya tarik dan kenyamanan rute, serta beberapa elemen yang melibatkan beberapa faktor, antara lain: jarak perjalanan, kemiringan jalur, kondisi jalur pejalan kaki, kelurusan jalur, dan faktor lain yang memudahkan saat berjalan (Monteiro \& Campos, 2012).

Menurut Untermann (1984), pada saat merancang jalur pejalan kaki yang baik, perlu diperhatikan kriteria desain jalur pejalan kaki yang diperlukan, yaitu terkait keamanan dan kenyamanan. Jalur pejalan kaki bukan hanya salah satu elemen perancangan kota yang hanya dianggap sebagai pembentuk keterhubungan antar aktivitas pada suatu area atau lokasi, juga bukan suatu usaha untuk mempercantik dan memperindah suatu area atau kawasan. Menurut Timboeleng \& Sendow (2015), jalur pejalan kaki akan mampu berfungsi baik terhadap pejalan kaki dalam melakukan kegiatan harus memenuhi ketentuan sebagai berikut:

1. Continuity (kelancaran): pada umumnya pejalan kaki segala usia lebih menyukai untuk berjalan memutar dimana pejalan kaki dapat diketahui saat datang dan pergi. Hal terpenting adalah rute menjadi lancar dan dapat dilakukan sewaktu-waktu.

2. Length (jarak/ lama/ panjang): jalur pejalan kaki tidak boleh terlalu panjang sehingga pejalan kaki dapat melalui beberapa pejalan kaki lain. Pejalan kaki harus dapat membuat kontak mata dengan pejalan kaki lainnya agar terjadi kontak sosial.

3. Width (lebar/ keluasan): beberapa pejalan kaki menyukai untuk jalan-jalan bersama, jadi sangatlah ideal jika jalur pejalan kaki memiliki jalur yang cukup lebar untuk 2 orang berpapasan satu dengan yang lainnya tanpa canggung menyela suatu percakapan. Jalur pejalan kaki yang baik dan humanis bila terdapat elemen pendukung atau street furniture. 
Keamanan dapat dilihat dari keamanan lalu lintas, keamanan menyeberang, kebutuhan untuk penyandang disabilitas, panjang jalur pejalan kaki, kecepatan perjalanan, penanda lalu lintas pejalan kaki, lebar jalur pejalan kaki, pengawas jalan, dan penerangan di malam hari (Southworth, 2005). Kategori aman pada jalur pejalan kaki bisa dilihat dari dua aspek, yaitu aspek fisik dan aspek manusia. Aspek fisik merupakan faktor yang mempengaruhi keamanan dari semua faktor selain faktor manusia, sedangkan faktor manusia bisa berupa perilaku, persepsi maupun preferensi (Nur \& Suwandono, 2015). Dalam penelitian ini menggunakan faktor preferensi. Untuk aspek fisik terdapat kriteria sebagai berikut (Asadishekari, Moeinaddini, \& Zaly, 2015):

1. Memiliki lebar ideal.

2. Adanya pembatas terhadap badan jalan maupun kendaraan bermotor.

3. Terdapat lampu untuk penerangan malam hari.

4. Kondisi permukaan (tekstur) rata, tidak licin, dan tidak rusak.

5. Tanpa hambatan/ penghalang dan keberadaan Pedagang Kaki Lima (PKL) tidak mengurangi dimensi jalur pejalan kaki.

6. Terdapat beda ketinggian dari lalu lintas kendaraan bermotor.

Kenyamanan pejalan kaki di jalur pejalan kaki dapat dilihat dari adanya kenikmatan berjalan tanpa adanya gangguan atau batasan dan lancar untuk digunakan sebagai kegiatan berjalan. Faktor-faktor yang mempengaruhi kenyamanan antara lain (Untermann, 1984):

1. Sirkulasi

Hal-hal yang terkait dengan sirkulasi pejalan kaki yaitu dimensi jalan dan jalur pejalan kaki, tempat asal dan tujuan sirkulasi pejalan kaki, maksud perjalanan, waktu, dan volume pejalan kaki.

2. Aksesibilitas

Meliputi kemudahan seseorang untuk mencapai suatu objek atau tujuan perjalanan. Hal-hal yang terkait aksesibilitas antara lain peniadaan hambatan, lebar jalur pejalan kaki, kawasan istirahat, kemiringan, curb ramps pada jalur pejalan kaki, ramps, permukaan, dan tekstur.

3. Gaya alam dan iklim

Merupakan keadaan alam sekitar lokasi studi dan iklim yang sedang terjadi, atau waktu pengambilan sampel. Meliputi curah hujan dan temperatur udara.

4. Kebersihan

Kebersihan jalur pejalan kaki dan lingkungan di sekitar jalur pejalan kaki dapat menambah daya tarik dan menambah kenyamanan pengguna jalur pejalan kaki.

5. Keindahan

Keindahan dapat dilihat dari berbagai persepsi pengguna yang berbeda-beda. Hal ini terkait dengan kepuasan batin dan panca indera. Keindahan dapat dilihat dari lingkungan alami, pemandangan di sekitar, dan keteraturan dalam penataan (Carmona, Heath, Oc, \& Tiesdell, 2003).

6. Street Furniture

Street furniture jalur pejalan kaki menurut Chiara J.D. \& Lee E Koppelman (1994) antara lain:

a. Lampu penerangan

b. Halte bus

c. Tanda penunjuk

d. Tempat sampah

e. Vegetasi dan pot bunga

Kawasan Blok $M$ merupakan kawasan dengan mobilitas yang tinggi. Hal ini dikarenakan pengaruh kawasan perkantoran dan sentra bisnis di Kawasan Blok $M$ yang sangat tinggi, sehingga jalur pejalan kaki yang aman dan nyaman sangat penting bagi pejalan kaki (Sandiputra, 2015). Hal ini mengakibatkan resiko kendaraan bermotor bertabrakan dengan pejalan kaki meningkat seiring bertambahnya jumlah kendaraan bermotor yang berinteraksi dengan pejalan kaki (Maghfur, 2015). Jika lingkungan tidak dapat menjamin keamanan pejalan kaki, maka upaya untuk meningkatkan kegiatan berjalan kaki dapat mengancam keselamatan pejalan kaki dan meningkatkan kematian dan cedera bagi pejalan kaki (Yu, 2015). 
Adanya alih fungsi jalur pejalan kaki sebagai tempat parkir liar di depan pertokoan dan digunakan pula sebagai tempat menunggu penumpang oleh tukang ojek online. Kondisi ini dapat mengganggu pergerakan pejalan kaki yang sedang di jalur pejalan kaki atau akan memasuki bangunan pertokoan, karena terhalang oleh kendaraan yang parkir. Terdapat pedagang kaki lima yang berjualan di jalur pejalan kaki, hal ini berpengaruh terhadap keamanan dan kenyamanan pejalan kaki. Keberadaan pedagang kaki lima ini dapat menghambat pergerakan pejalan kaki. Dengan beberapa persoalan tersebut, maka diperlukan penentuan prioritas indikator dalam merencanakan jalur pejalan kaki di Kota Jakarta secara umum dan Kawasan Blok M (Jl. Panglima Polim, Jl. Melawai, dan Jl. Sultan Iskandarsyah) khususnya dengan melibatkan pendapat para ahli dan pejalan kaki sebagai masukan penting dalam merencanakan jalur pejalan kaki yang aman dan nyaman. Hal ini dikarenakan pejalan kaki merupakan pengguna yang merasakan langsung kondisi jalur pejalan kaki.

Beberapa penelitian yang dilakukan sebelumnya lebih menekankan pada penyediaan jalur pejalan kaki dan fasilitasnya secara umum tanpa menggabungkan preferensi para ahli dan preferensi pejalan kaki. Dalam penelitian ini, pembahasan akan lebih menekankan pada menentukan prioritas indikator terkait keamanan dan kenyamanan berdasarkan preferensi pejalan kaki dan ahli, agar dalam perencanaannya pemerintah tidak hanya melibatkan pendapat para ahli, tetapi juga melibatkan pendapat dari masyarakat yang berjalan kaki. Hal ini dikarenakan pejalan kaki yang menggunakan dan merasakan langsung kondisi dari jalur pejalan kaki. Oleh karena itu tujuan dari penelitian ini adalah untuk menentukan prioritas indikator dalam merencanakan jalur pejalan kaki.

\section{DATA DAN METODE}

\subsection{Wilayah Penelitian}

Wilayah studi penelitian ini berada di kawasan Blok M Jakarta Selatan, yang berfungsi sebagai pusat kegiatan sekunder di wilayah Kota Administrasi Jakarta Selatan. Lokasi penelitian difokuskan pada jalur pejalan kaki di kawasan Blok M, yaitu Jl. Panglima Polim, Jl. Melawai, dan Jl. Sultan Iskandarsyah. Jl. Panglima Polim dan Jl. Sultan Iskandarsyah merupakan jalan arteri sekunder, sedangkan J. Melawai merupakan jalan kolektor sekunder.

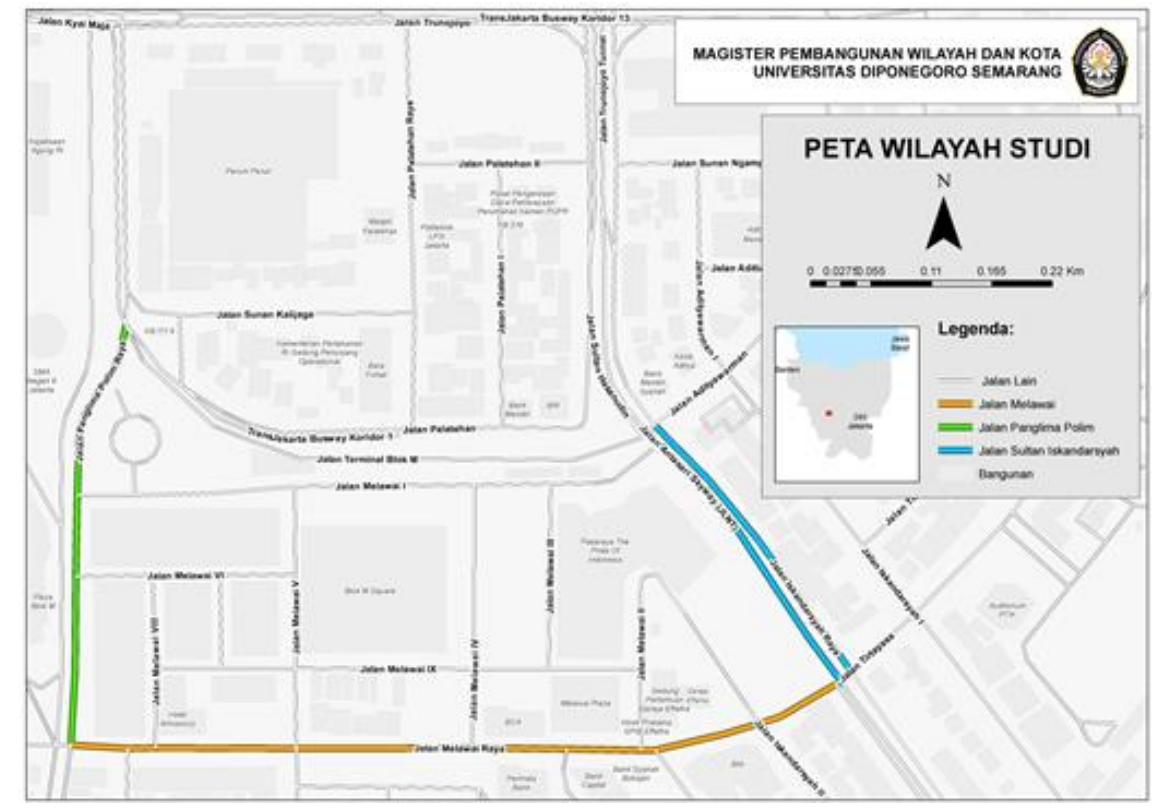

Gambar 1. Peta Lokasi Penelitian

Pengambilan data kuesioner dilakukan kepada 2 (dua) kelompok, yaitu kelompok pejalan kaki dan kelompok ahli yang paham jalur pejalan kaki terkait aspek keamanan dan kenyamanan. Pada kelompok pejalan kaki memiliki 96 responden yang terbagi rata untuk masing-masing jalan. Disisi lain, kelompok ahli 
memiliki 10 (sepuluh) responden yang terdiri dari 7 (tujuh) responden pejabat pemerintah, 1 (satu) responden akademisi, dan 2 (dua) responden komunitas atau lembaga.

\subsection{Metode Penelitian}

Metode penelitian yang digunakan adalah deskriptif kuantitatif, yaitu memberikan gambaran yang lebih detail terkait karakteristik jalur pejalan kaki dan kondisi keamanan serta kenyamanan dari jalur pejalan kaki. Pengambilan data primer menggunakan kuesioner diberikan kepada responden serta survei lapangan yang dilakukan oleh peneliti. Teknik pengolahan data menggunakan metode Importance Performance Analysis (IPA) yang bertujuan mengetahui preferensi pejalan kaki terhadap kualitas keamanan dan kenyamanan jalur pejalan kaki serta metode Analytic Hierarchi Process (AHP) yang bertujuan untuk pengambilan keputusan dengan memperhatikan faktor-faktor persepsi, preferensi, pengalaman, dan intuisi.

\subsubsection{Importance Performance Analysis (IPA)}

Model IPA (Importance Perfomance Analisys) bertujuan untuk mengukur hubungan antara persepsi konsumen dan prioritas peningkatan kualitas produk/ jasa yang dikenal juga sebagai quadrant analysis (analisis kuadran) (Martilla \& James, 2013). Model ini dibagi menjadi 4 (empat) kuadran seperti terlihat pada gambar berikut:

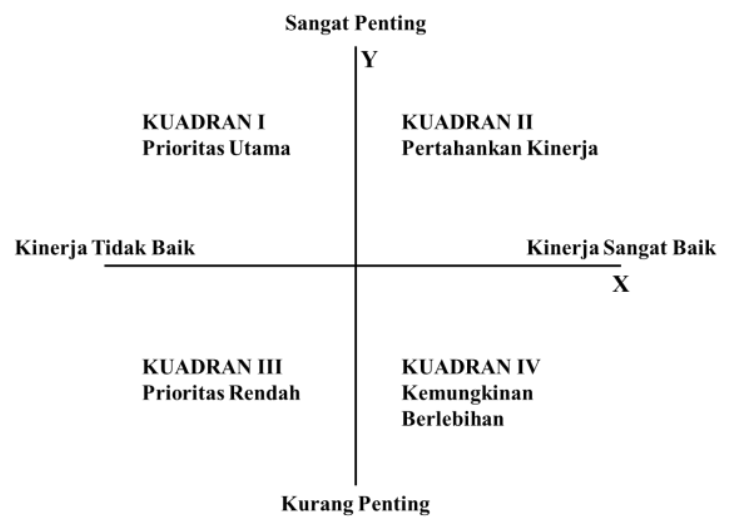

Gambar 2. Kuadran Importance Performance Analysis (IPA) (Martilla \& James, 2013)

a. Kuadran I : Prioritas Utama.

Atribut yang berada pada kuadran ini sebagai faktor yang sangat penting dibandingkan faktor lainnya, pihak pemerintah berkewajiban memberikan sumber daya yang lebih dan memberikan perhatian yang lebih pada faktor yang berada pada kuadran ini.

b. Kuadran II : Pertahankan Kinerja.

Faktor yang berada di kuadran ini dapat dianggap penting dan diharapkan sebagai faktor penunjang untuk kepuasan pejalan kaki, sehingga pihak pengambil kebijakan atau pihak pemerintah berkewajiban memastikan bahwa proses kinerja yang dikelolanya dapat terus mempertahankan prestasi yang dicapai

c. Kuadran III : Prioritas Rendah.

Faktor yang berada pada kuadran ini mempunyai tingkat prioritas yang rendah daripada faktor lainnya, sehingga pihak pemerintah tidak perlu lebih memprioritaskan pada faktor ini.

d. Kuadran IV : Berlebihan.

Faktor yang berada pada kuadran ini dianggap tidak terlalu penting, sehingga pihak pemerintah perlu mengalokasikan faktor yang dianggap terkait pada kuadran ini kepada faktor lain yang membutuhkan prioritas penanganan lebih tinggi.

\subsubsection{Analytic Hierarchy Process (AHP)}

Metode Analytic Hierarchy Process (AHP) merupakan salah satu metode yang dapat digunakan dalam sistem pengambilan keputusan dengan memperhatikan faktor-faktor persepsi, preferensi, pengalaman, 
dan intuisi (Saaty, 2008). AHP menggabungkan penilaian-penilaian dan nilai-nilai pribadi ke dalam satu cara yang logis. AHP direkomendasikan sebagai salah satu metode analisis multi kriteria yang akan digunakan untuk pengambilan keputusan atau prioritas pengaturan di sektor publik dan swasta (Jung, Kwon, \& Kim, 2012).

\section{HASIL DAN PEMBAHASAN}

3.1. Karakteristik Jalur Pejalan Kaki

Penilaian karakteristik jalur pejalan kaki tidak lepas dari kriteria tekait aspek fisik yang mempengaruhi keamanan dan kenyamanan. Keamanan dilihat dari keamanan lalu lintas, keamanan menyeberang, kebutuhan untuk penyandang disabilitas, panjang jalur pejalan kaki, kecepatan perjalanan, penanda lalu lintas pejalan kaki, lebar jalur pejalan kaki, pengawas jalan, dan penerangan di malam hari (Southworth, 2005).

Berdasarkan faktor yang mempengaruhi keamanan, maka dapat dijabarkan bahwa karakteristik jalur pejalan kaki di kawasan Blok M meliputi geometri jalur pejalan kaki dan volume pejalan kaki. Geometri jalur pejalan kaki di Kawasan Blok $M$ meliputi ukuran dan dimensi, jenis material yang digunakan, serta keberadaan fasilitas penyandang disabilitas. Rekapitulasi kondisi geometri jalur pejalan kaki di kawasan Blok M dapat dilihat pada Tabel 1.

Tabel 1. Rekapitulasi Kondisi Geometri Jalur Pejalan Kaki Di Kawasan Blok M (Hasil Analisis, 2017)

\begin{tabular}{|c|c|c|c|c|c|c|c|}
\hline \multirow[b]{2}{*}{ No. } & \multirow[b]{2}{*}{ Nama Jalan } & \multicolumn{2}{|c|}{ Dimensi } & \multirow{2}{*}{$\begin{array}{l}\text { Jenis Material } \\
\text { Permukaan }\end{array}$} & \multirow{2}{*}{$\begin{array}{c}\text { Ubin } \\
\text { Pemandu }\end{array}$} & \multirow[b]{2}{*}{ Street Furniture } & \multirow{2}{*}{$\begin{array}{c}\text { Tempat } \\
\text { Penyeberangan }\end{array}$} \\
\hline & & $\begin{array}{l}\text { Lebar } \\
\text { (meter) }\end{array}$ & $\begin{array}{l}\text { Tinggi } \\
\text { (meter) }\end{array}$ & & & & \\
\hline 1 & Jl. Panglima Polim & $0,50-1,00$ & $0,10-0,30$ & Beton & Tidak ada & $\begin{array}{l}\text { Terdapat: Lampu } \\
\text { Penerangan }\end{array}$ & Zebra cross \\
\hline 2 & Jl. Melawai & $2,00-5,00$ & $0,20-0,30$ & $\begin{array}{l}\text { Beton dan Beton } \\
\text { Berongga }\end{array}$ & Ada & $\begin{array}{l}\text { Terdapat: Tempat Duduk, } \\
\text { Tempat Sampah, Bollard, } \\
\text { Vegetasi, Lampu } \\
\text { Penerangan, dan Halte }\end{array}$ & Zebra cross \\
\hline 3 & Jl. Sultan Iskandarsyah & $1,00-3,00$ & $0,30-0,50$ & $\begin{array}{l}\text { Beton, Blok Beton } \\
\text { (Paving Block), dan } \\
\text { Ubin }\end{array}$ & Tidak ada & $\begin{array}{l}\text { Terdapat: Tempat } \\
\text { Sampah, Bollard, vegetasi, } \\
\text { Pohon Peneduh }\end{array}$ & $\begin{array}{l}\text { Zebra cross dan } \\
\text { Jembatan } \\
\text { Penyeberangan } \\
\text { Orang (JPO) }\end{array}$ \\
\hline
\end{tabular}

Volume pejalan kaki pada di kawasan Blok M dapat dilihat pada Tabel 2.

Tabel 2. Volume Pejalan Kaki Di Kawasan Blok M (Hasil Analisis, 2017)

\begin{tabular}{|c|l|c|c|}
\hline \multirow{2}{*}{ No. } & \multicolumn{2}{|c|}{ Nama Jalan } & \multicolumn{2}{|c|}{ Volume Pejalan Kaki } \\
\cline { 3 - 4 } & & Weekdays (orang/jam) & Weekend (orang/jam) \\
\hline 1 & Jl. Panglima Polim & 340 & 436 \\
\hline 2 & Jl. Melawai & 796 & 904 \\
\hline 3 & Jl. Sultan Iskandarsyah & 719 & 832 \\
\hline
\end{tabular}

3.2. Analisis Keamanan dan Kenyamanan Jalur Pejalan Kaki, Preferensi Pejalan Kaki

Aspek fisik merupakan faktor yang mempengaruhi keamanan dari semua faktor selain faktor manusia, sedangkan faktor manusia bisa berupa perilaku, persepsi maupun preferensi (Nur \& Suwandono, 2015). Dalam penelitian ini menggunakan faktor preferensi. Untuk aspek fisik terdapat kriteria sebagai berikut (Asadi-shekari et al., 2015):

1. Memiliki lebar ideal.

2. Adanya pembatas.

3. Keberadaan lampu penerangan.

4. Kondisi permukaan (tekstur) rata, tidak licin, dan tidak rusak.

5. Tanpa hambatan/ penghalang dan keberadaan Pedagang Kaki Lima (PKL) tidak mengurangi dimensi jalur pejalan kaki. 
6. Terdapat beda ketinggian dari lalu lintas kendaraan bermotor.

Kenyamanan pejalan kaki di jalur pejalan kaki dapat dilihat dari adanya kenikmatan berjalan tanpa adanya gangguan atau batasan dan lancar untuk digunakan sebagai kegiatan berjalan. Faktor-faktor yang mempengaruhi kenyamanan antara lain (Untermann, 1984): a) Sirkulasi; b) Aksesibilitas; c) Gaya alam dan iklim; d) Kebersihan; e) Keindahan; dan f) Street Furniture. Faktor keamanan dan kenyamanan tersebut digunakan sebagai indikator dalam penentuan preferensi pejalan kaki dan para ahli.

Analisis ini terbagi menjadi penilaian kinerja jalur pejalan kaki dan penilaian harapan jalur pejalan kaki saat hari biasa (weekdays) dan hari libur (weekend). Berikut merupakan diagram yang mengelompokkan indikator dari variabel keamanan dan kenyamanan pada jalur pejalan kaki di kawasan Blok $\mathrm{M}$.

\begin{tabular}{|c|c|}
\hline $\begin{array}{l}\text { Weekdays: (2) Adanya Pembatas, (4) } \\
\text { Kondisi Permukaan (Tekstur), dan } \\
\text { (12) Terdapat Street Furniture }\end{array}$ & $\begin{array}{l}\text { Weekdays: (1) Memiliki Lebar Ideal, } \\
\text { (3) Terdapat Lampu Penerangan, (7) } \\
\text { Sirkulasi/Kemudahan Pergerakan, } \\
\text { dan (8) Aksesibilitas }\end{array}$ \\
\hline $\begin{array}{l}\text { Weekend: (5) Tanpa Hambatan/ } \\
\text { Penghalang dan (12) Terdapat Street } \\
\text { Furniture }\end{array}$ & $\begin{array}{l}\text { Weekend: (3) Terdapat Lampu } \\
\text { Penerangan dan (10) Kebersihan }\end{array}$ \\
\hline $\begin{array}{l}\text { Weekdays: (5) Tanpa Hambatan/ } \\
\text { Penghalang, (10) Kebersihan, (11) } \\
\text { Keindahan }\end{array}$ & $\begin{array}{l}\text { Weekdays: (6) Terdapat Beda } \\
\text { Ketinggian, dan (9) Gaya Alam dan } \\
\text { Iklim }\end{array}$ \\
\hline $\begin{array}{l}\text { Weekend: (1) Memiliki Lebar Ideal, } \\
\text { (4) Kondisi Permukaan (Tekstur), (7) } \\
\text { Sirkulasi/Kemudahan Pergerakan, } \\
\text { dan (11) Keindahan }\end{array}$ & $\begin{array}{l}\text { Weekend: (2) Adanya Pembatas, (6) } \\
\text { Terdapat Beda Ketinggian, (8) } \\
\text { Aksesibilitas, dan (9) Gaya Alam dan } \\
\text { Iklim }\end{array}$ \\
\hline
\end{tabular}

Gambar 1. Perbandingan Kuadran Jalur Pejalan Kaki JI Panglima Polim Weekday dan Weekend (Hasil Analisis, 2017)

\begin{tabular}{|c|c|}
\hline $\begin{array}{l}\text { Weekdays: (3) Terdapat Lampu } \\
\text { Penerangan, (4) Kondisi Permukaan } \\
\text { (Tekstur), dan (12) Terdapat Street } \\
\text { Furniture }\end{array}$ & $\begin{array}{l}\text { Weekdays: (1) Memiliki Lebar Ideal, } \\
\text { (2) Adanya Pembatas, (6) Terdapat } \\
\text { Beda Ketinggian, (7) Sirkulasi/ } \\
\text { Kemudahan Pergerakan, dan (10) } \\
\text { Kebersihan }\end{array}$ \\
\hline $\begin{array}{l}\text { Weekend: (12) Terdapat Street } \\
\text { Furniture }\end{array}$ & $\begin{array}{l}\text { Weekend: (1) Memiliki Lebar Ideal } \\
\text { dan (3) Terdapat Lampu Penerangan }\end{array}$ \\
\hline $\begin{array}{l}\text { Weekdays: (5) Tanpa Hambatan/ } \\
\text { Penghalang, (8) Aksesibilitas, (11) }\end{array}$ & Weekdays: (9) Gaya Alam dan Iklim \\
\hline $\begin{array}{l}\text { Weekend: (2) Adanya Pembatas, (5) } \\
\text { Tanpa Hambatan/Penghalang, (9) } \\
\text { Gaya Alam dan Iklim, (10) } \\
\text { Kebersihan, dan (11) Keindahan }\end{array}$ & $\begin{array}{l}\text { Weekend: (4) Kondisi Permukaan } \\
\text { (Tekstur), (6) Terdapat Beda } \\
\text { Ketinggian, (7) Sirkulasi/ } \\
\text { Kemudahan Pergerakan, dan (8) } \\
\text { Aksesibilitas }\end{array}$ \\
\hline
\end{tabular}

Gambar 2. Perbandingan Kuadran Jalur Pejalan Kaki Jl Melawai Weekday dan Weekend (Hasil Analisis, 2017) 


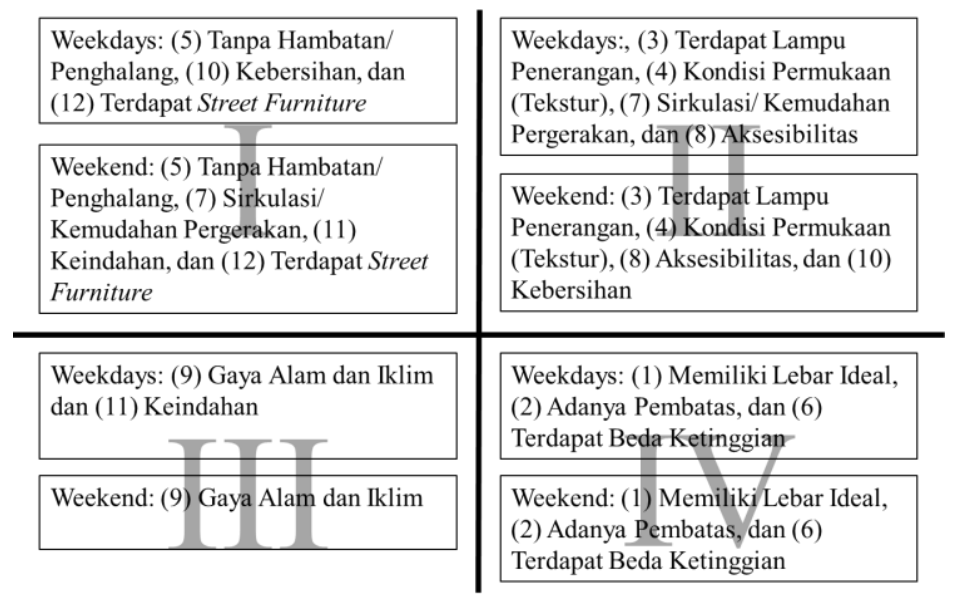

Gambar 3. Perbandingan Kuadran Jalur Pejalan Kaki Jl Sultan Iskandarsyah Weekday dan Weekend

(Hasil Analisis, 2017)

Berdasarkan hasil analisis yang telah dilakukan pada ketiga jalur pejalan kaki di Kawasan Blok M baik pada hari biasa (weekdays) maupun hari libur (weekend), dapat disimpulkan bahwa indikator yang perlu menjadi prioritas utama dalam merencanakan jalur pejalan kaki adalah sebagai berikut.

Tabel 3. Prioritas Indikator Berdasarkan Preferensi Pejalan Kaki (Hasil Analisis, 2017)

\begin{tabular}{|c|c|c|c|c|c|}
\hline \multirow{2}{*}{ No } & \multirow{2}{*}{ Ruas Jalan } & \multicolumn{2}{|c|}{ Weekdays } & \multicolumn{2}{|c|}{ Weekend } \\
\hline & & Keamanan & Kenyamanan & Keamanan & Kenyamanan \\
\hline 1. & $\begin{array}{l}\text { Jl. Panglima } \\
\text { Polim }\end{array}$ & $\begin{array}{l}\text { - } \text { Adanya } \\
\text { Pembatas } \\
\text { - } \text { Kondisi } \\
\text { Permukaan } \\
\text { (Tekstur) }\end{array}$ & $\begin{array}{l}\text { - Terdapat } \\
\text { Street } \\
\text { Furniture }\end{array}$ & $\begin{array}{l}\text { - Tanpa } \\
\text { Hambatan/ } \\
\text { Penghalang }\end{array}$ & $\begin{array}{l}\text { - Terdapat } \\
\text { Street } \\
\text { Furniture }\end{array}$ \\
\hline 2. & Jl. Melawai & $\begin{array}{l}\text { - } \text { Terdapat } \\
\text { Lampu } \\
\text { Penerangan } \\
\text { - Kondisi } \\
\text { Permukaan } \\
\text { (Tekstur) } \\
\end{array}$ & $\begin{array}{l}\text { - Terdapat } \\
\text { Street } \\
\text { Furniture }\end{array}$ & & $\begin{array}{l}\text { - Terdapat } \\
\text { Street } \\
\text { Furniture }\end{array}$ \\
\hline 3. & $\begin{array}{l}\text { Jl. Sultan } \\
\text { Iskandarsyah }\end{array}$ & $\begin{array}{l}\text { - Tanpa } \\
\text { Hambatan/ } \\
\text { Penghalang }\end{array}$ & $\begin{array}{l}\text { - Kebersihan } \\
\text { - Terdapat } \\
\text { Street } \\
\text { Furniture }\end{array}$ & $\begin{array}{l}\text { - Tanpa } \\
\text { Hambatan/ } \\
\text { Penghalang } \\
\text { - Sirkulasi/ } \\
\text { Kemudahan } \\
\text { Pergerakan }\end{array}$ & $\begin{array}{l}\text { - Keindahan } \\
\text { - Terdapat } \\
\text { Street } \\
\text { Furniture }\end{array}$ \\
\hline
\end{tabular}

3.3. Analisis Keamanan dan Kenyamanan Jalur Pejalan Kaki, Preferensi Para Ahli

Penentuan prioritas indikator dalam merencanakan jalur pejalan kaki berdasarkan atas variabel keamanan dan kenyamanan. Keamanan terkait dengan kondisi lebar ideal jalur pejalan kaki, keberadaan pembatas, keberadaan lampu penerangan, kondisi permukaan, ketiadaan hambatan, dan terdapat beda ketinggian. Sedangkan Kenyamanan terkait dengan sirkulasi/ kemudahan pergerakan, aksesibilitas, gaya alam dan iklim, kebersihan, keindahan, dan street furniture.

Berdasarkan hasil pembobotan prioritas menurut preferensi 10 (sepuluh) responden dari kelompok ahli, didapatkan bobot dari masing-masing variabel yang dapat dilihat pada Tabel 4 . 
Tabel 4. Prioritas Variabel Berdasarkan Kelompok Ahli (Hasil Analisis, 2017)

\begin{tabular}{|c|l|c|c|}
\hline No. & \multicolumn{1}{|c|}{ Responden } & Keamanan & Kenyamanan \\
\hline 1 & Kepala Dinas Bina Marga (DBM), Eselon 2 & 0,500 & 0,500 \\
\hline 2 & $\begin{array}{l}\text { Kepala Bidang Kelengkapan Jalan dan Jaringan } \\
\text { Utilitas (KPJJU) DBM, Eselon 3 }\end{array}$ & 0,500 & 0,500 \\
\hline 3 & $\begin{array}{l}\text { Kepala Seksi Perencanaan Bidang KPJJU DBM, } \\
\text { Eselon 4 }\end{array}$ & 0,500 & 0,500 \\
\hline 4 & $\begin{array}{l}\text { Kepala Seksi Pengendalian Bidang KPJJU DBM, } \\
\text { Eselon 4 }\end{array}$ & $\mathbf{0 , 9 0 0}$ & 0,100 \\
\hline 5 & $\begin{array}{l}\text { Kepala Suku Dinas Bina Marga (SDBM) Kota Adm. } \\
\text { Jakarta Selatan, Eselon 3 }\end{array}$ & $\mathbf{0 , 9 0 0}$ & 0,100 \\
\hline 6 & $\begin{array}{l}\text { Kepala Seksi KPJJU SDBM Kota Adm. Jakarta } \\
\text { Selatan, Eselon 4 }\end{array}$ & $\mathbf{0 , 8 0 0}$ & 0,200 \\
\hline 7 & $\begin{array}{l}\text { Kepala Seksi Perencanaan Direktorat Jenderal } \\
\text { Cipta Karya Kementerian (DJCK) PUPR, Eselon 4 }\end{array}$ & $\mathbf{0 , 8 3 3}$ & 0,167 \\
\hline 8 & $\begin{array}{l}\text { Dosen Perencanaan Wilayah dan Kota (PWK) } \\
\text { Universitas Trisakti, Jakarta (Pengamat } \\
\text { Perkotaan) }\end{array}$ & $\mathbf{0 , 8 3 3}$ & 0,200 \\
\hline 9 & $\begin{array}{l}\text { ITDP Indonesia } \\
\text { Rata-rata }\end{array}$ & $\mathbf{0 , 8 0 0}$ & 0,167 \\
\hline 10 & Gerakan Aksesibilitas Umum Nasional (GAUN) & $\mathbf{0 , 7 0 0}$ & $\mathbf{0 , 2 9 3}$ \\
\hline & \multicolumn{2}{|c|}{} \\
\hline
\end{tabular}

Pembobotan dilakukan pada masing-masing indikator keamanan dan kenyamanan menurut prioritas responden kelompok ahli. Berikut merupakan diagram prioritas indikator keamanan dan kenyamanan jalur pejalan kaki menurut kelompok para ahli.

(1)

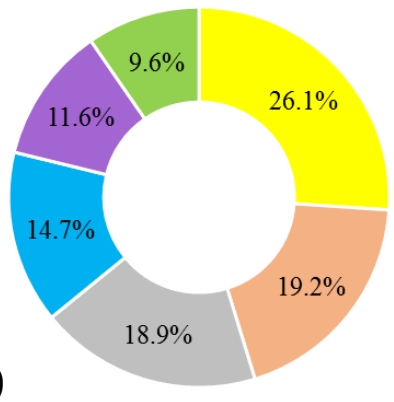

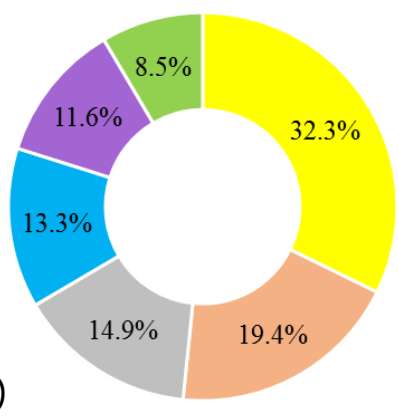

(2)

\author{
Aksesibilitas \\ $\square$ Sirkulasi \\ $\square$ Street Furniture \\ - Kebersihan \\ - Keindahan \\ $\backsim$ Gaya Alam dan Iklim
}

Gambar 3. Diagram Prioritas Indikator (1) Keamanan (2) Kenyamanan Jalur Pejalan Kaki (Hasil Analisis, 2017)

Berdasarkan tingkat keamanan dan kenyamanan menurut preferensi para ahli bahwa kondisi permukaan (tekstur) dan aksesibilitas jalur pejalan kaki sebagai prioritas utama indikator dalam merencanakan jalur pejalan kaki.

Tabel 5. Prioritas Indikator Berdasarkan Preferensi Para Ahli (Hasil Analisis, 2017)

\begin{tabular}{|c|l|l|}
\hline No & \multicolumn{1}{|c|}{ Keamanan } & \multicolumn{1}{c|}{ Kenyamanan } \\
\hline 1. & Kondisi Permukaan (Tekstur) & Aksesibilitas \\
\hline 2. & Terdapat Beda Ketinggian & Sirkulasi/ Kemudahan Pergerakan \\
\hline 3. & Tanpa Hambatan/ Penghalang & Terdapat Street Furniture \\
\hline 4. & Memiliki Lebar Ideal & Kebersihan \\
\hline 5. & Terdapat Lampu Penerangan & Keindahan \\
\hline 6. & Adanya Pembatas & Gaya Alam dan Iklim \\
\hline
\end{tabular}




\section{KESIMPULAN}

Terdapat perbedaan penentuan prioritas indikator dalam merencanakan jalur pejalan kaki antara kelompok pejalan kaki dan kelompok para ahli. Perbedaan ini dikarenakan kelompok pejalan kaki menilai prioritas indikator berdasarkan kondisi yang dirasakan secara langsung pada jalur pejalan kaki, sedangkan kelompok ahli menilai prioritas indikator berdasarkan teori dan best practice tanpa mengamati lebih jauh kondisi yang ada pada jalur pejalan kaki. Berdasarkan preferensi pejalan kaki bahwa peniadaan hambatan/ penghalang dan keberadaan street furniture merupakan prioritas utama indikator, sedangkan berdasarkan preferensi para ahli bahwa kondisi permukaan (tekstur) dan aksesibilitas merupakan prioritas utama indikator. Hal ini menunjukkan bahwa dalam merencanakan jalur pejalan kaki selama ini belum mengakomodir kebutuhan yang diinginkan oleh pejalan kaki. Tidak heran banyak jalur pejalan kaki yang sudah terbangun tidak berfungsi secara optimal.

Kedepannya dalam merencanakan jalur pejalan kaki harus lebih ditekankan kepada aspek pemenuhan kebutuhan pejalan kaki tanpa mengesampingkan pendapat para ahli. Indikator yang harus diprioritaskan adalah peniadaan hambatan/ penghalang antara lain Pedagang Kaki Lima (PKL) yang tidak mengurangi dimensi jalur pejalan kaki dan kondisi permukaan (tekstur) rata, tidak licin, dan tidak rusak terkait tingkat keamanan, sedangkan di sisi lain indikator keberadaan street furniture (tempat duduk, tempat sampah, bollard, vegetasi, lampu penerangan, dan halte) dan indikator aksesibilitas terkait kemudahan dalam mencapai suatu objek atau tujuan perjalanan terkait tingkat kenyamanan juga harus diutamakan. Dengan demikian, rekomendasi yang dapat diberikan bagi Pemerintah Kota Jakarta terkait penentuan prioritas indikator dalam merencanakan jalur pejalan kaki adalah perlunya pelibatan akademisi, komunitas/ lembaga, pejalan kaki, dan pihak-pihak yang berkepentingan lainnya; melibatkan instansi terkait dalam penegakan aturan setelah terbangunnya jalur pejalan kaki; menempatkan ruang interaksi sosial ataupun PKL pada ruang jalur pejalan kaki dengan titik/ jarak tertentu yang memiliki lebar besar atau di halaman gedung/ perkantoran; penyediaan fasilitas pendukung atau street furniture harus seiring dengan perencanaan fisik jalur pejalan kaki; pengintegrasian jalur pejalan kaki dengan guna lahan di sekitar jalur pejalan kaki, dan transportasi publik yang dapat dijangkau oleh pejalan kaki dengan mudah.

\section{PERNYATAAN RESMI}

Terima kasih kepada seluruh pihak, khususnya Pemerintah Provinsi DKI Jakarta yang telah memberi kesempatan dan dukungan pembiayaan.

\section{REFERENSI}

Asadi-shekari, Z., Moeinaddini, M., \& Zaly, M. (2015). Pedestrian safety index for evaluating street facilities in urban areas. Elsevier, 74, 1-14. https://doi.org/http://dx.doi.org/10.1016/j.ssci.2014.11.014

Anonimous, 2014. Permak Trotoar di Blok M, Jaksel Usulkan Rp 80 M. Available at: https://metro.tempo.co/ read/630112/permak-trotoar-di-blok-m-jaksel-usulkan-rp-80-m

Barman, J., \& Daftardar, C. (2010). Planning for Sustainable Pedestrian Infrastructure with upcoming MRTS - An Appraisal of Walkability Conditions in Lucknow. Institute of Town Planners, India, 7(3), 64-76.

Carmona, M., Heath, T., Oc, T., \& Tiesdell, S. (2003). Public Places - Urban Spaces. Architectural Press.

Chiara, D. Joseph. and Koppelman, E. Lee. 1994. Standar Perencanaan Tapak, Terjemahan Januar Hakim, Jakarta: Penerbit Erlangga.

DKI Jakarta, P. Peraturan Daerah DKI Jakarta Nomor 1 Tahun 2014 tentang Rencana Detail Tata Ruang dan Peraturan Zonasi (2014).

Jung, B. D., Kwon, Y., \& Kim, H. (2012). The Analysis of Priorities of ITS Using Analytic Hierarchy Processes. Evaluation.

Kaban, Jhon Syah Putra, 2016. Penataan Trotoar Mendukung Penggunaan Transportasi Umum. Available at: http://www.beritajakarta.id/read/33619/ penataan-trotoar-mendukung-penggunaan-transportasiumum\#.WZ7QYz5JbIV 
Maghfur, A. (2015). Keselamatan Pejalan kaki: Manual Keselamatan Jalan Bagi Pengambil Keputusan dan Praktisi. World Health Organization.

Martilla, J. A., \& James, J. C. (2013). Importance-Performance Analysis. American Marketing Association, 41(1), 77-79.

Martiyanti Erna, 2016. 48 Trotoar di Jakarta akan Diperbaiki. Available at: http://www.beritajakarta.id /read/29653/48_trotoar_di_jakarta_akan_diperbaiki\#.WZ7QWD5JbIV

Monteiro, F. B., \& Campos, V. B. G. (2012). 15th meeting of the EURO Working Group on Transportation A proposal of indicators for evaluation of the urban space for pedestrians and cyclists in access to mass transit station. Procedia - Social and Behavioral Sciences, 54, 637-645. https://doi.org/10.1016/j.sbspro.2012.09.781

Nur, Z. A., \& Suwandono, D. (2015). Kajian Keamanan Jalur Pejalan Kaki Di Jalan Arteri Sekunder Berdasarkan Aspek Fisik Dan Masyarakat ( Studi Kasus : Jalan Pemuda Kabupaten Klaten ). Ruang Undip, 1(1), 1-10. https://doi.org/HTTP://DX.DOI.ORG/10.14710/RUANG.1.4.1-10

Pratama, N. (2014). Studi perencanaan trotoar di dalam lingkungan kampus universitas sriwijaya inderalaya. Jurnal Teknik Sipil Dan Lingkungan Universitas Sriwijaya, 2(2), 272-277.

Saaty, T. L. (2008). Decision making with the analytic hierarchy process. Int. J. Services Sciences, 1(1).

Sandiputra, Rio, 2015. Pedestrian Kuningan dan Blok M Akan Ditata. Available at: http://www.beritajakarta. $\mathrm{id} / \mathrm{read} / 7799 /$ pedestrian-kuningan-dan-blok-m-akan-ditata\#.WZ_ sWD5JblU

Southworth, M. (2005). Designing the Walkable City. JOURNAL OF URBAAN PLANNING AND DEVELOPMENT, 131(December), 246-257. https://doi.org/10.1061/(ASCE)0733-9488(2005)131:4(246)

Timboeleng, J. A., \& Sendow, T. K. (2015). Analisa Tingkat Pelayanan Trotoar Ditinjau Dari Laju Arus Pada Ruas Jalan Sam Ratulangi Manado Untuk Segmen Ruas Jalan Rs Siloam - Monumen Zero Point. Jurnal Sipil Statik, 3(2).

Untermann, Richard K. 1984. Accommodating the Pedestrian: Adapting Towns and Neighborhoods for Walking and Biking. Van Nostrand Reinhold: New York.

Yu, C. Y. (2015). Built environmental designs in promoting pedestrian safety. Sustainability (Switzerland), 7(7), 9444-9460. https://doi.org/10.3390/su7079444 